\title{
Surgical Treatment of Gynecomastia: How to Achieve Optimal Results in Mild to Moderate Cases?
}

\section{Yordan P Yordanov* \\ Adella Aesthetic, Sofia, Bulgaria}

*Corresponding author: Yordan P Yordanov, Adella Aesthetic, organiztion, Bulgaria, 11, Tsar Boris III Blvd. ap.37, Sofia, Bulgaria, Tel: 887560054; Email: yordanov_vma@abv.bg

\section{Conceptual paper}

Volume 2 Issue 4

Received Date: September 01, 2018

Published Date: October 04, 2018

\section{Abstract}

Surgical treatment of gynecomastia is one of the most common but very demanding procedures in the field of the male plastic surgery. Achieving an effective and aesthetically acceptable outcome is of a paramount importance in this group of patients. The minimally invasive combined surgical approach consisting of suction-assisted liposuction (SAL) and direct surgical excision allows for effective removal of fat and glandular tissue and provides excellent cosmetic results with low risk of complications or recurrences in patients with small to moderate breast enlargement with skin excess. The aim of this brief clinical study is to put an emphasis on the tips for achieving best results in surgical treatment of mild to moderate gynecomastia in minimally invasive manner.

Keywords: Gynecomastia; Surgical excision; Suction-assisted liposuction; Combined surgical approach

\section{Introduction}

Gynecomastia is defined as a benign enlargement of the male breast which may be unilateral or bilateral [1]. It is estimated that gynecomastia can be found in approximately $50 \%$ of all males, irrespective of age and underlying clinical conditions [2]. This medical condition has many identifiable causes including drugs, metabolic disorders, adrenal and testicular tumors, primary and secondary hypogonadism, hyperthyroidism, and renal diseases among others though most cases are idiopathic (Table 1) [3-5].

Gynecomastia can be a source of significant anxiety and embarrassment especially in younger males and the surgical treatment is the main approach for correction of this condition [4-10]. The aim of the present article is to summarize and put an emphasis on the tips for achieving best results in the surgical treatment of mild to moderate gynecomastia according to the author's preliminary experience. 


\section{Causes of Gynecomastia}

\section{Developmental / Physiologic}

- Neonatal

- Pubertal

- Aging

2. Drug-induced

3. Hypogonadism (decreased androgen synthesis or increased androgen resistance)

$\begin{array}{ll}- & \text { Primary } \\ - & \text { Acquired (trauma, infection, torsion, radiation exposure, mumps, chemotherapy) } \\ - & \text { Congenital } \\ - & \text { Secondary } \\ - & \text { Hypogonadotropic hypogonadism } \\ - & \text { Kallmann syndrome } \\ - & \text { Pituitary failure (infarction, infection, neoplasm) }\end{array}$

4. Tumors (increased estrogen production)

- $\quad$ Steroid-producing (adrenal, testis)

- Human chorionic gonadotropin-producing (testis and others)

- $\quad$ Aromatase-producing (testis)

- Bronchogenic carcinoma

5. Systemic

- $\quad$ Thyrotoxicosis (altered testosterone / estrogen binding)

- $\quad$ Renal failure (acquired testicular failure)

- $\quad$ Cirrhosis (increased substrate for peripheral aromatization)

- Adrenal (adrenocorticotropic hormone deficiency or congenital adrenal hyperplasia)

6. Congenital disorders

- Klinefelter syndrome

- $\quad$ Enzyme defects of testosterone synthesis (may be late onset)

- $\quad$ Vanishing testis syndrome (anorchia)

- $\quad$ Androgen resistance syndromes

- $\quad$ True hermaphroditism and related conditions

- Increased peripheral tissue aromatase

7. Familial

8. Miscellaneous

- HIV

- $\quad$ Chest wall trauma

- $\quad$ Psychological stress

- $\quad$ Spinal cord injury

- $\quad$ Malnutrition / refeeding (increased substrate for peripheral aromatization)

- Herpes zoster infection

- $\quad$ Cystic fibrosis

- $\quad$ Alcoholism

- $\quad$ Myotonic dystrophy

9. Idiopathic

Table 1: Etiology of gynecomastia. 


\section{Patients and Methods}

A retrospective analysis based on the clinical records and photo-documentation was made recruiting male patients of the author's practice with breast enlargement for the period of five years. Demographic and medical information on the patients was collected, including age, regular habits, comorbidities, endocrine status, current and past medication, and family history. For surgical treatment were considered patients with at least one year of persisting gynecomastia, namely patients with stable gynecomastia. Prior to surgery all the patients were evaluated by mamologist with diagnostic imaging methods- ultrasound and/or mammography. All patients had their photograph taken and were evaluated for the grade of their breast enlargement. Gynecomastia was grouped using the classification of Simons and associates, with division into four grades [11]:

- Grade I: Small enlargement without skin excess;

- Grade IIa: Moderate enlargement without skin excess;

-Grade IIb: Moderate enlargement with minor skin excess;

-Grade III: Marked enlargement with excess skin, mimicking female breast ptosis.

Patients with Simon grade III gynecomastia (with significant enlargement and ptosis) require skin reduction with significant impact on the final aesthetic outcome being the aesthetically unpleasant scars the main sequels. This group of patients was excluded from the study. Both written and verbal consent was obtained from all the patients for the surgical procedure, possible risks and complications, and the utilization of the patients' personal data and photos. The surgical technique was the same in all the patients. A combined surgical approach was applied as previously described by the author including suction-assisted liposuction (SAL) and minimally invasive breast tissue reduction $[5,10]$. A standardized regimen in the post-operatory period was followed: moderate compression with a compression garments was applied which is worn for about 3 to 4 weeks. In the cases in which it corresponds, the patients are allowed to perform cardiovascular exercise and lightweight training after approximately that period of time (3 weeks). In all the cases the Excisional sample was pathologically studied. The minimal follow-up of the study was selected to be of 12 months.

\section{Results}

A total of 19 patients (38 male breasts) with age range between 18 and 49 (mean age 32.1 y) (Figure 1) were operated for the selected period of the study. In 10 of then a steroid use was the reason of the breast enlargement (Figure 2) and in the rest of the patients the Gynaecomastia was idiopathic. In one of the patients an interesting phenomenon was observed- a secondary progression of preexisting gynecomastia after an acute trauma of the breast was registered. This case has been reported by the senior author and the team [5]. There were 17 uncomplicated procedures, as represented by the case depicted on Figure 3. Two patient developed postoperative unilateral seroma formation, which was resolved with aspiration and compression. Both patients were not strictly wearing the compression garment in the first few days after the surgery. The histopathological study of the samples revealed no malignancies in all of the cases. No recurrence occurred in the period of postoperative follow-up. One patient did not present in the one year checking up but did present at the 18 months follow-up with no concerns. All the patients were satisfied with the final result and would recommend the procedure to others.

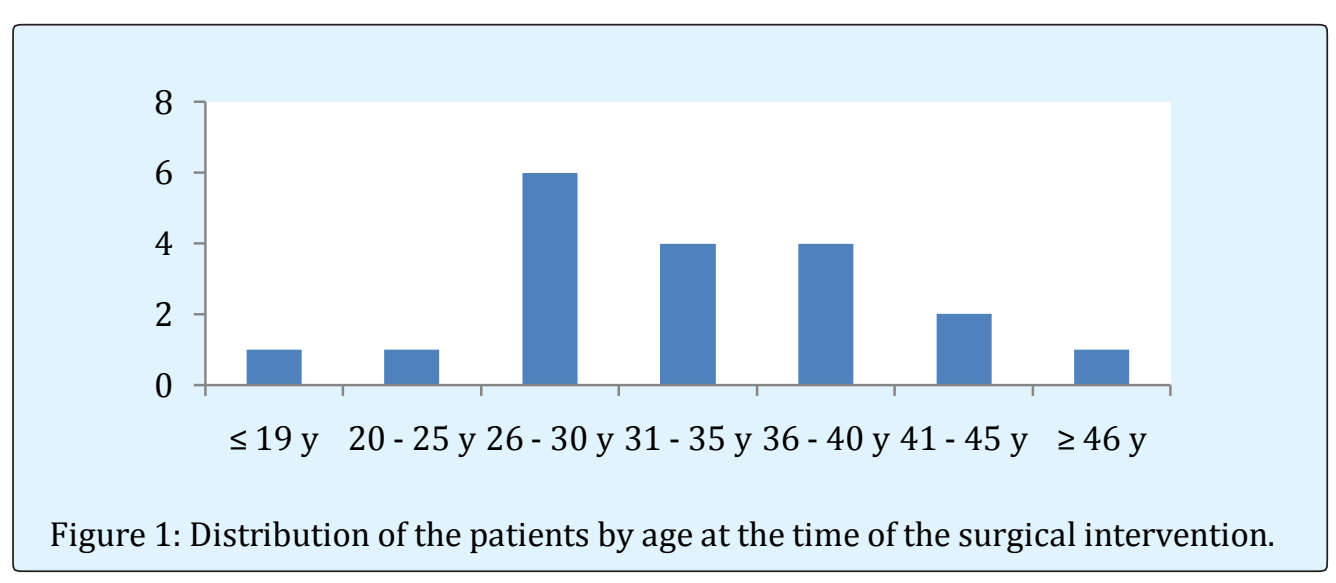

Yordan P Yordanov. Surgical Treatment of Gynecomastia: How to Achieve Optimal Results in Mild to Moderate Cases?. Int J Surg Surgical Tech 2018, 2(4): 000129. 


\section{International Journal of Surgery \& Surgical Techniques}

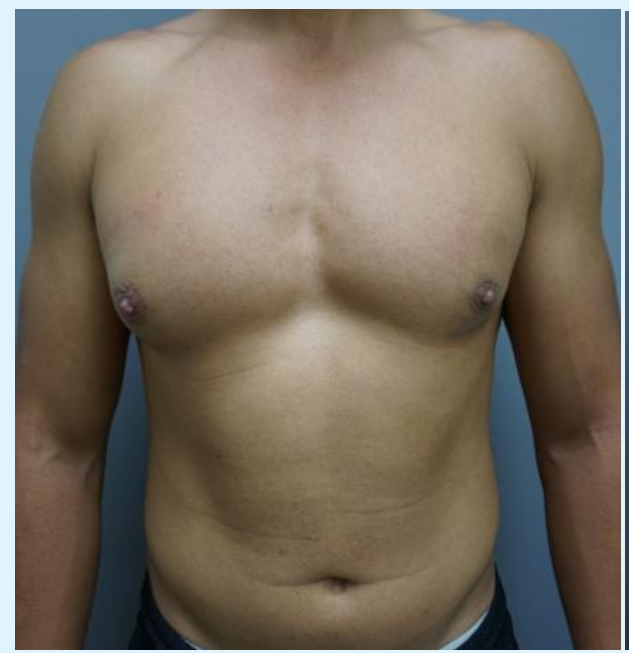

I

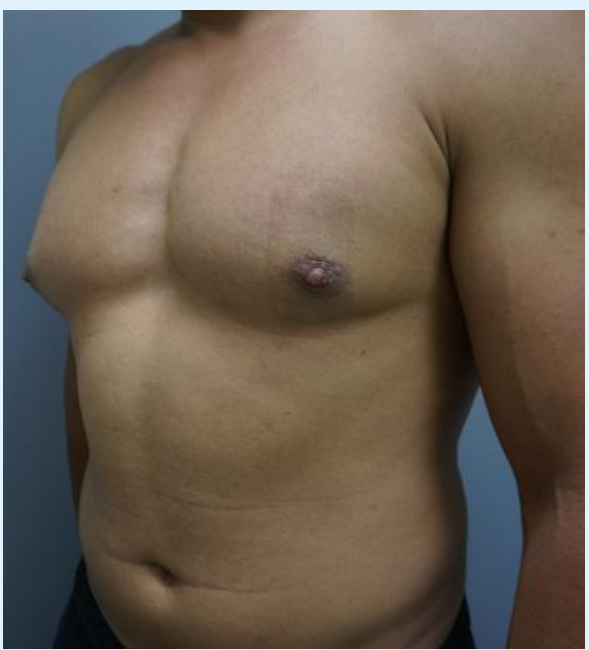

II

Figure 2: 32-year old patient with Simon's type I-II a gynecomastia with asymmetry due to anabolic steroids use.

\section{Discussion}

Our main task in surgical treatment of gynecomastia has always been achieving a good balance between effectiveness of the selected approach and the optimal aesthetic outcome and as uneventful postoperative period as possible. The author of the present article truly believes that the optimal aesthetic outcome could be achieved by applying a combination of a minimally invasive Excisional technique and SAL (Figure 3), as stated by others too [12]. Direct excision alone does not give good shaping the chest wall and the addition of suction lipectomy is often needed for best contouring. Furthermore, the liposuction by its own leads to skin retraction [13] which is especially beneficial to the patients with Simon IIb gynecomastia.

Based on the author's experience and observations from one hand and the discussions in the literature from the other hand, the following tips could be useful in the daily practice:

- Well performed informed consent is the first step to having grateful patients.
- Combined surgical approach consisting of SAL and minimally invasive direct surgical excision gives optimal results.

- Use local tumescent infiltration with Klein solution or similar prior to the SAL.

- Perform SAL first. A small incision on the lateral chest wall between the middle and the medial axillary line gives comfortable approach with the cannula and good aesthetics.

- Keep the pectoralis fascia intact during the surgical dissection.

- Preserve a button of dense tissue is under the areola in order to maintain the nipple-areola vascularity and to prevent unpleasant concavity deformation.

- Meticulous hemostasis is of paramount importance.

- Consider placing a closed-suction drain for 12-24 hours if necessary.

- Apply compression garment staring in the immediate postop period for 2 to 3 weeks.

- Wait at least 6 months before any intention for surgical correction of irregularities or deformities. 


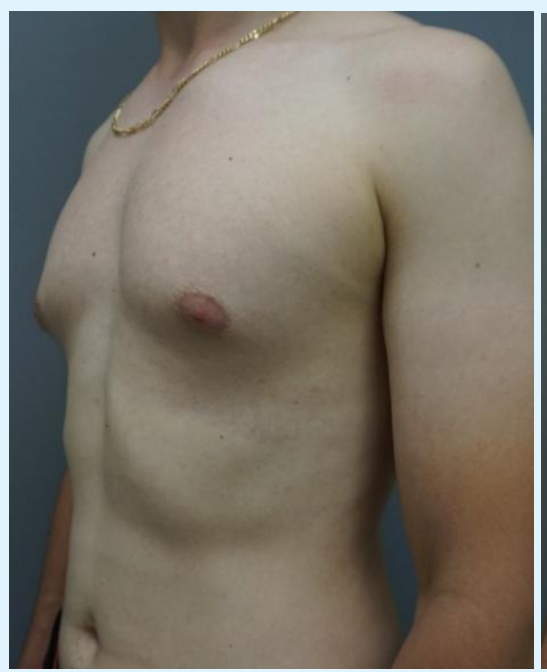

A

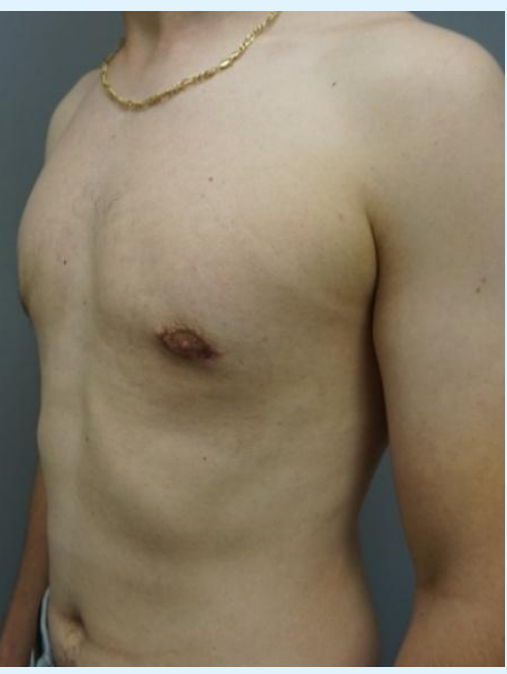

B

Figure 3: 27-year old patient with Simon's type I idiopathic gynecomastia persisting from the puberty: (A) Preoperative evaluation; (B) Postoperative result at two months after applying a minimally invasive combined surgical approach consisting of suction-assisted liposuction (SAL) and direct surgical excision.

\section{Conclusion}

Gynecomastia is a benign condition and usually no aggressive treatment is needed. Even multiple etiologic factors could play a role, most cases are idiopathic and the surgical management is a first-line approach to these patients. In order to achieve good aesthetic outcome in mild to moderate cases a minimally invasive surgical technique including combination of SAL and direct excision is a treatment of choice.

\section{Conflicts of Interest: None.}

\section{References}

1. Lista F, Ahmad J (2011) Gynecomastia. In: Spear SL, Willey SC, Robb GLE, et al. (Eds.), Surgery of The

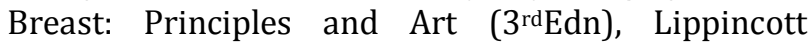
Williams \& Wilkins; Philadelphia, pp: 1205-1210.

2. Sansone A, Romanelli F, Sansone M, Lenzi A, Di Luigi L (2017) Gynecomastia and hormones. Endocrine 55(1): 37-44.

3. Cohen IK, Pozez AL, Mckeown JE (1991) Gynecomastia. In E. Fl. Courtiss (Ed): Male Aesthetic Surgery. St. Louis: Mosby.
4. Rohrich RJ, Ha RY, Kenkel JM, Adams WP (2003) Classification and Management of Gynecomastia: Defining the Role of Ultrasound-Assisted Liposuction. Plast Reconstr Surg 111(2): 909-923.

5. Yordanov Y, Shef A, Hristoskova R, Albena Fakirova (2016) Post-Traumatic Onset of Secondary Progression Of Gynecomastia. Eur J Plast Surg 39(5): 387-390.

6. Reyes RJ, Zicchi S, Hamed H, Chaudary MA, Fentiman IS (1995) Surgical Correction of gynaecomastia in bodybuilders. Br J Clin Pract 49(4): 177-179.

7. Lee JH, Kim IK, Kim TG, Kim YH (2012) Surgical Correction of Gynecomastia with Minimal Scarring. Aesthetic Plast Surg 36(6): 1302-1306.

8. Handschin AE, Bietry D, Hüsler R, Banic A, Constantinescu M (2008) Surgical Management of Gynecomastia- A 10-Year Analysis. World J Surg 32(1): 38-44.

9. Wong KY, Malata CM (2014) Conventional Versus Ultrasound-Assisted Liposuction in Gynaecomastia Surgery: A 13-Year Review. J Plast Reconstr Aesthet Surg 67(7): 921-926. 


\section{International Journal of Surgery \& Surgical Techniques}

10. Yordanov Y, Lasso JM, Shef A (2015) Combined Surgical Treatment of Gynecomastia. Acta Med Bulg 42(1): 43-48.

11. Simon BE, Hoffman S, Kahn S (1973) Classification and Surgical Correction of Gynecomastia. Plast Reconstr Surg 51(1): 48-52.
12. Babigian A, Silverman RT (2001) Management of gynecomastia due to use of anabolic steroids in Bodybuilders. Plast Reconstr Surg 107(1): 240-242.

13. Coleman WP, Hendry SL (2006) Principles of Liposuction. Semin Cutan Med Surg 25(3): 138-144.

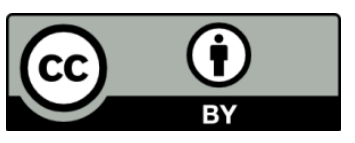

